\title{
Assessment of the communicative competence in a productive collective activity within digital transformation
}

\author{
Elena Murugova* and Denis Murugov \\ Don State Technical University, 344000, Rostov-on-Don, Russia
}

\begin{abstract}
In the context of digital transformation, it is necessary to educate a person who will be able to work productively in an uncertain situation with the information deficit possessing soft skills and appropriate hard skills, without which it is impossible to proceed to the educational community with a high level of spiritual, legal and professional culture. The communicative competence is of great importance. The objectives of this research were to study components of communicative competence and diagnostic approach as well as to suggest the way of competence assessment/Search for the mechanisms to manage communicative competence of students is an important task in the development of higher education. The solution to this problem will increase the efficiency of training of future specialists in the period of active development of new communication technologies and create the conditions for successful professional and personal fulfillment. The research presented in the paper is based on the hypothesis that the formation of communicative competence of university students is determined by the interconnectedness of competencies which make up the structure of communicative competence through the sequencing of the stages of development of communicative competence and determination of the algorithm of formation of communicative competence in higher education
\end{abstract}

\section{Introduction}

Nowadays the influence of high educational establishments on the innovative development of Russia is limited because of the low volume of research and contribution of our graduates to the development of innovative technologies. About 39\% of high establishments have poor digital infrastructure. To provide a free access towards qualitative educational resources the common federal marketplace with the digital content (Mooch, conference courses, virtual laboratories, simulators) the support of individual students' development is created. Digital technologies implementation is connected with the inevitable changes in the field of Artificial Intellect, IT, Big Data, block chain technologies, etc. Changes are focused on the content and models of education and competence assessment. The leading type of thinking in the 21 st century is the complex systematic and critical thinking. The key unit is problem and problematization. Nowadays only, the

*Corresponding author: den1610@yandex.ru 
network structures can be viable. For an efficient management situation, this means that you need to network a number of educational institutions where every student can choose its own track. The individual educational programs are applied for the university transformation. It is known that to move up the ladder of career fast nowadays you need to develop two important things: emotional intellect and ability to analyze and work with data. The majority of employers employ their staff by the soft skills. That is, you can be from a famous university, but if you have a low emotional intellect, most likely you will not build an efficient career. What does it mean? Students need to develop the ability to communicate effectively, find an approach to different people, be able to work with emotions, be proactive, empathetic, conscious and reflective. Emotional intellect plays an important role even almost more important than IQ. If you look at the labor market and how the business is developing, there is a significant shortage of people who can analyze data professionally. That is, a great number of people who can process data are in demand in business. Having these skills you can get a good job without any work experience. Business wants to receive analysis, forecasts based on data. What is the best way to assess a person's potential? Some recruiters propose a formula for assessing the potential that is based on such qualities as:

- ability to analyze and build hypotheses;

- belief in oneself, the ability to convince, the skills of a real leader;

- ability to interact with others;

- communication;

- change (the world is changing and we must adjust and learn new skills quickly);

- drive;

- analysis

Communicative competence complex by itself demonstrates the capability of a person to generate and transmit meanings, exchange and store information using various sign systems. The investigation process shows the search of researchers to manage communicative competence of students [1], to develop a new English communicative competence diagnostic approach [2], to apply modern technologies of its assessment [3], distinguish its types in different fields [4-7], to identify the role of texts [8] and multimodality of university students [9]. The main stages of communicative competence grasp collective interaction, relationships with people who are in a different situation, reflection communication, understanding, sense, effective understanding, schematization, pure thinking (operating with certain signs and ideal objects), analysis of the real situation and reflection. Very often, it is connected only with the linguistic competence, peculiar for the language study [10]. We separate such activities as communication, thinking, reflection and understanding. Moreover, it is indicated that thinking technologies - schematization, prolematization, obiectivation, positioning - are such specific "modes" of operation of the entire set of processes. This technological scheme was preceded by a difficult period of research evolution. From today's perspective, it is relevant to highlight three key points:

- the thinking processes should be separated from understanding;

- reflection is treated as the effect of changing positions;

- communication can be presented as a system of acts.

Interest in the processes of communication was derived from philosophy and social sciences of the early twentieth century. Experiments showed that children, successfully solving a direct problem, are much more likely to have trouble with solving the inverse, which suggests that the way to solve problems cannot be reduced to accounting operations. To solve the problem, a student must first understand its conditions, choose/build a solution method, must be able to associate the text with both the situation described in the problem and the mental methods of solving this type of problems, including categorical schemes. In other words, understanding means a vision of the connections between the elements of the task and the practical situation, sufficient to find a way to solve it. Later, Georgy Petrovich 
Schedrovitsky admits that "understanding is wider than thinking" and that "understanding" is the main background process in the investigation [11]. In empirical text studies containing the expression of the problem-solving processes and problems with which the Moscow Methodological Circle began to work, reflection was initially considered as a mechanism for deploying reasoning, which is opposed to the formal (primarily logical) rules governing the organization of this reasoning. Everything that did not fit into these formal rules, operations and procedures, objectively is presented in the empirical experience of reasoning/thinking. The effect of reflection can be explained because of the positional change. The relationship between reflection and thinking becomes the most important focus of consideration in the Moscow Methodological Circle [11].

Thinking is done at the intersection of several different processes and accordingly has several different independent sources.

- thinking becomes from reflection; and this link must be considered both in terms of the genesis of thinking as a whole and in terms of the implementation of each particular act of thought.

- each act and each process of thinking represents the realization of a certain set of mental tools and norms fixed in culture.

The means and norms that we implement in each process of thought must correspond to those reflexive functions that set and determine the place of this process of thought within the activity. The appeal to the problems of communication and the phenomenon of morality that grows in the processes of communication and cooperation was largely provoked by the personal experience of communication failure. "The problematic situation of speech and ways of achieving mutual understanding in the course of communication has become an occasion for reflection" [12].

Subjectivity appears only because of intersubjective interaction. The abstract confrontation between the subject and the object, internal and external, is formed in a person, only perceiving social interactions. Language is an objective social phenomenon. Therefore, a growing individual can form the inner center of life only in communicatively created interpersonal relations. The phenomenon of self-consciousness should be something original.

\section{Materials and Methods}

Communication presupposes collective interaction that implies relations with people in similar or different situations. You cannot imagine communicative competence development without reflection (turning the communicator's attention to himself and his consciousness; a representation of what and how I did; transference of experience from the outer world to himself). Communication expresses reflection in speech or text. Without understanding that focuses on a new action done according to the text, the perception of communication is impossible. Comprehension process allows dividing the text, relating text to a situation. Schematization gives general consideration of an object or phenomenon. Pure thinking contributes to the operation with certain signs and ideal objects. Analysis of the real situation puts the thought scheme of ideal objects on reality. Within the research, the diagnostic approach is used. It consists of 6 steps;

1) design of problem-based situations for the communicative competence assessment;

2) define major indicators;

3) compile learning outcomes with the descriptors;

4) diagnose English communicative competence of students;

5) analyze data;

6) provide feedback to teachers and students. 
Moreover, there are various methods involved in this diagnostic approach such as teacher questionnaire, student self-assessment, checklist and descriptors.

\section{Results}

The first step in evaluation is elaboration of learning outcomes referring to reflection, understanding, communication, sense, effective understanding, pure thinking, situation analysis. The second stage is to present descriptors that will help to assess the growth delta of the competence. In the process of assessment of the communicative competence, certain indicators were elaborated in accordance with Table 1:

Table 1. Communicative competence assessment

\begin{tabular}{|c|c|c|}
\hline Competence & Learning outcomes & Descriptors \\
\hline \multirow[t]{4}{*}{ Communicative } & $\begin{array}{l}\text { To orient in } \\
\text { communicative means } \\
\text { (reflection) }\end{array}$ & $\begin{array}{l}\text { To be capable to start the } \\
\text { process of } \\
\text { communication joining } \\
\text { the collective activity; } \\
\text { To be capable to define a } \\
\text { role in communication } \\
\text { To be capable to generate } \\
\text { and convey meanings and } \\
\text { ideas; } \\
\text { To be capable to see all } \\
\text { the content in the } \\
\text { retrospect }\end{array}$ \\
\hline & $\begin{array}{l}\text { To understand the speech } \\
\text { and text efficiently }\end{array}$ & $\begin{array}{l}\text { To be capable to reveal } \\
\text { the meaning of complex } \\
\text { contents; } \\
\text { To be capable to } \\
\text { understand the verbal } \\
\text { texts; } \\
\text { To be capable to see all } \\
\text { the contents in a } \\
\text { retrospective }\end{array}$ \\
\hline & $\begin{array}{l}\text { To communicate using } \\
\text { different semiotics }\end{array}$ & $\begin{array}{l}\text { To be capable to build a } \\
\text { new action according to } \\
\text { the text; } \\
\text { To be capable to express } \\
\text { your ideas in speech }\end{array}$ \\
\hline & To schematize & $\begin{array}{l}\text { To be capable to divide } \\
\text { and connect parts of the } \\
\text { text; to be capable to carry } \\
\text { out search, storage and } \\
\text { information } \\
\text { systematization; } \\
\text { To be capable to } \\
\text { schematize and reveal } \\
\text { new meanings; } \\
\text { To be capable to } \\
\text { understand the verbal } \\
\text { texts; }\end{array}$ \\
\hline
\end{tabular}




\begin{tabular}{|l|l|l|}
\hline $\begin{array}{l}\text { To operate with the ideal } \\
\text { objects (pure thinking) }\end{array}$ & $\begin{array}{l}\text { To be capable to operate } \\
\text { productively with certain } \\
\text { signs sign forms and } \\
\text { ideal objects in the } \\
\text { situations of uncertainty; }\end{array}$ \\
\hline $\begin{array}{l}\text { To analyze situation } \\
\text { (reflection) }\end{array}$ & $\begin{array}{l}\text { To be capable to build } \\
\text { related speech texts based } \\
\text { on the ideal reality of } \\
\text { thinking according to the } \\
\text { rules of logics; } \\
\text { To be capable to deploy } \\
\text { and argue; } \\
\text { To be capable to do } \\
\text { attempts to formulate the } \\
\text { point of view; } \\
\text { To be capable to criticize } \\
\text { the ideas of others; } \\
\text { To be capable to do } \\
\text { attempts to reach mutual } \\
\text { understanding } \\
\text { communication in } \\
\text { To be capable to build } \\
\text { his own and perceive the } \\
\text { other people's thoughts }\end{array}$ \\
\hline
\end{tabular}

This list of descriptors should not be limited. It is important to establish the level of performance of the chosen indicators: the basic level, the high level and the highest level. And only after that develop evaluation criteria for each level. The descriptor can be performed or not. Competence assessment is considered by the average arithmetic indicator of the manifestation of activities performed by the student. The competence development is seen only in different students' activities. Measurements after each module allowsbuilding the student's competency map.

\section{Discussion}

To assess the communicative competence you should suggest the conditions for the productive activity that contribute to the communicative competence development [13-17]. A teacher should contributes to relevant environment creation for the communicative competence development [18]. For the learning outcomes assessment we should use IT technologies: computer assessment programs, situational tasks, simulators. Testing should include problem-based tasks that allow assessing the level of obtained knowledge, skills and gained experience. In some cases, it is relevant to use portfolio that presents the level of students' achievements. Participation of the students in different activities can demonstrate the development of the mastery level. The usage of roleplaying activities contributes to the development of the communicative competence as well as working in a team. The environments may be real and unreal and in order to solve a problem you should identify it, put a definite goal, choose necessary tools or if necessary create them to overcome communicative barrier. In the process of role-playing, you should choose your position, determine your decision, communicating with different members of a team, and come to an agreement, present your point of view. Sometimes the role you are to play does notcorrespond your point of view, and you are to go out from the conflict zone. The 
uncertain situations prepare graduates to act productively in a true to life environment and lack of necessary tools. Project-based learning allows assessing the level of communicative competence, critical and analytical thinking, teamwork, creativity, and self-assessment. Creating a project, you develop intercultural collaboration taking part in the collective activity because you have to listen to somebodies point of view and consider it showing empathy and tolerance. You have to formulate, explain and defend your standpoint (f. ex. choosing the best questions). The ability to integrate and distinguish relevant information, schematize it provides conditions for the successful communication. With the growth of the task complexity, the level of competence development is increasing. F. ex. for the basic level of communicative competence we may suggest mini-project "My family tree" for the students with the level A1 of mastering English, for the highest level of communicative competence development - project "My life on the You tube channel" for the students with the level B1 of mastering English. The ways of tracking communicative competence development are connected with the supervision during discussion participation, fulfillment of the group tasks with their further reflection in the student's portfolio. The creation of uncertain situations in the project work contributes to the knowledge obtaining in the process of activity, problem identification and goal setting, critical thinking, making conclusions and standing point of view, assessing the results. The material is centered on the key ideas. The usage of digital technologies, active methods of teaching allows to fix own deficits, to self-assess personal activities. The activity is mainly organized in small groups. A teacher brings a student to an independent solution of problems, facilitates him and organizes an efficient way of competence development. Supervising a project a teacher participates with the students in discussions, helps them to present their point of view. A student is not afraid of expressing his opinion, make a mistake. The process of competence development is oriented on personal development, self-education and self-development. The application of digital assessment allows making this process efficient, economizes efforts and time, and motivates students to upgrading and amelioration.

\section{Conclusions}

Communicative competence is a complex competence that is the capability of a person to generate, range and transfer information with the usage of different sign systems. Communicative competence reveals only in the collective activity. We distinguish such key components as communication and understanding, reflection and schematization, operation with definite signs and ideal objects, convergence of real and unreal situation. Reflection helps a student to be aware of what he is really doing. A student can generate ideas, understand what he really knows and does. He sees the content in a retrospect. The great focus is done on the idea understanding. Productive actions are major criteria for understanding A student can compile texts, integrating ideas, trying to achieve mutual understanding in communication. A role of a teacher to create relevant environments for the communicative competence assessment. The communicative competence is forming in the process of productive activity when a student based on his knowledge, skills and personal experience tries to overcome problematic situation finding new necessary tools in accordance with the certain aims. The first step in evaluation is elaboration of learning outcomes such as: reflection, understanding, communication, sense, effective understanding, pure thinking, situation analysis. The second stage is to present indicators and descriptors that will help to assess the growth delta of the competence. The knowledge of digital technologies allows assessing the level of the competence development from the basic one up to the highest. Learning outcomes helps to assess communicative competence with the usage of the active methods and innovative digital technologies. Project work, different cases, roleplays, complex problems solving, research projects, practical activities, 
creative tasks helps to create favorable conditions for the communicative competence development.

\section{References}

1. N. Lukyanova, Y. Daneykin, N. Daneikina, Procedia - Social and Behavioral Sciences 191, 759-763 (2015). doi: https://doi.org/10.1016/j.sbspro.2015.11.761.

2. K. Poolsawada, S. Kanjanawasee, J. Wudthayagorn, Procedia - Social and Behavioral Sciences 154, 250 - 253 (2014). doi: 10.1016/j.sbspro.2014.10.145.

3. Z. Bissenbayeva, M. Aurenova, Z. Aubakirova, E. Uaidullakyzy, Modern Technologies of Communicative Competence Formation. https://doi.org/10.1016/j.sbspro.2014.01.1025 (2014).

4. U.R. Cetinavci, Language \& Communication 57, 14-21 (2017). https://doi.org/10.1016/j.sbspro.2012.06.082.

5. L.C. Moore, Language \& Communication 3 (29), 244-253 (2009). https://doi.org/10.1016/j.langcom.2009.02.006.

6. T.B. Mikheeva, E.V. Murugova, SHS Web Conf. 70, 07003 (2018). URL: https://www.shsconferences.org/articles/shsconf/pdf/2019/11/shsconf_ictdpp2018_070 03.pdf. doi: https://doi.org/10.1051/shsconf/20197007003

7. P. Parrado-Martínez, Sánchez-Andújar, International Review of Economics Education 35, 100192 (2020). https://doi.org/10.1016/j.iree.2020.100192.

8. S.L. Heggernes, Language \& Communication, 57, 14-21. (2021) https://doi.org/10.1016/j.edurev.2021.100390

9. F. Coccetta, System 77, 19-27 (2018). https://doi.org/10.1016/j.system.2018.01.004.

10. C. Vorwerg, International Encyclopedia of the Social \& Behavioral Sciences. 2nd.ed. 294-301 (2015). https://doi.org/10.1016/B978-0-08-097086-8.53042-6.

11. G. Shchedrovitsky, Organizational thinking: ideology, methodology, technology (3rd ed. Studio Publishing House, Moscow, 2014).

12. J. Habermas, Individual. Culture. Society 3, 207-217 (2001).

13. N.F. Efremova, Problems of the development of modern science: theory and practice. Cartero Publishing House, Spain. 194-197. URL: https://istina.ipmnet.ru/publications/article/170026704/ (2018).

14. N.F. Efremova, A.A. Huseynova, S.V. Shvedova, SHS Web Conf. 04003 (2019). ICTDPP-2019. URL: https://www.shsconferences.org/articles/shsconf/pdf/2019/11/shsconf_ictdpp2018_04003.pdf. doi:https://doi.org/10.1051/shsconf/20197004003.

15. N.F. Efremova, A.A. Huseynova, E3S Web of Conferences 175, 15015 (2020). INTERAGROMASH 202. doi: https://doi.org/10.1051/e3sconf/202017515015

16. N. Usmanova, T. Shindina, A. Basharina, Procedia - Social and Behavioral Sciences 116, 4780-4784. (2014). https://doi.org/10.1016/j.sbspro.2015.11.701

17. C. Eldera, T. McNamaraa, H. Kim, J. Pill, Sato, Procedia - Social,a Behavioral Sciences 214, 565-570 (2015). doi: https://doi.org/10.1016/j.langcom.2016.12.005

18. E.V. Murugova, T. B. Mikheeva, E3S Web of Conferences 210, 18095 (2020). doi: https://doi.org/10.1051/e3sconf/202021018095 